\title{
A Microchip Electrophoresis Device Integrated with the Top-bottom Antiparallel Electrodes of Indium Tin Oxide to Detect Inorganic Ions by Contact Conductivity
}

\author{
Sheng-Yao Chang,* Ming-Yuan LeE,* and Ching-Chou WU ${ }^{*, * * \dagger}$ \\ *Department of Bio-industrial Mechatronics Engineering, National Chung Hsing University, Taichung City 402, \\ Taiwan, $R O C$ \\ **Innovation and Development Center of Sustainable Agriculture, National Chung Hsing University, \\ Taichung City 402, Taiwan, ROC
}

\begin{abstract}
A microchip electrophoresis (ME) device with off-channel contact conductivity detection $\left(\mathrm{C}^{2} \mathrm{D}\right)$ was constructed using top-bottom antiparallel indium tin oxide (ITO) electrodes and a cross-type microchannel. The 500-m wide top-bottom antiparallel decouplers were found to effectively decrease the interference of the electrophoretic current. The cross-type microchannel was formed by bonding the patterned negative photoresist microstructures and the two top-bottom opposed ITO-deposited glass substrates. Five seconds of $150 \mathrm{~V} / \mathrm{cm}$ injection field and the $100 \mathrm{~V} / \mathrm{cm}$ separation field equipped with the $\mathrm{C}^{2} \mathrm{D}$ of $\mathrm{AC} 200 \mathrm{mV}$ excitation voltage provided adequate $\mathrm{ME}$ operational parameters to obtain the $\mathrm{K}^{+}$and $\mathrm{Na}^{+}$peaks separation. The ME devices obtained good coefficients in a range of $11000 \mu \mathrm{M}$ for the $\mathrm{K}^{+}$and $\mathrm{Na}^{+}$detection. The calculated limit of detection was $1 \mu \mathrm{M}$. This design for off-channel and top-bottom antiparallel electrodes shows that $\mathrm{C}^{2} \mathrm{D}$ ME devices have great potential for the measurement of inorganic ions.
\end{abstract}

Keywords Contact conductivity detection, microchip electrophoresis, off-channel, top-bottom antiparallel electrode

(Received March 13, 2018; Accepted June 13, 2018; Published November 10, 2018)

\section{Introduction}

Microchip electrophoresis (ME) has been used in different micro-analytical applications because of its rapid separation, ease of mass production, high portability, and high compatibility with various detection techniques. ME has been widely applied to the biomedical, food production and environmental engineering fields for the determination of proteins, ${ }^{1}$ peptides, ${ }^{2}$ DNA, ${ }^{3}$ neurotransmitters, ${ }^{4}$ inorganic and organic ions, ${ }^{5,6}$ vitamins $^{7}$ and reactive nitrogen species. $^{8}$ In particular, electrochemical electrodes, including amperometry and conductometry, are among the most widely used ME detection strategies due to their ease of operation and flexible integration to form a $\mu$ TAS. Compared to amperometric electrodes, conductometric electrodes with ME could have great promise for the detection of noneletroacitve species, including inorganic $^{9-14}$ and organic ions ${ }^{15}$ by measuring the conductivity difference between the analytes and the BGE.

Conductometric electrodes equipped with ME use one of two strategies: contact detection and contactless detection. ${ }^{16}$ Capacitively coupled contactless conductivity detection $\left(\mathrm{C}^{4} \mathrm{D}\right)$ requires a more complex electrode configuration to decrease the unavoidable stray capacitance and higher AC detecting voltages (tens of Volts) than the contact conductivity detection $\left(\mathrm{C}^{2} \mathrm{D}\right) \cdot{ }^{9,17}$ Moreover, the sensitivity of $\mathrm{C}^{4} \mathrm{D}$ is determined by the permittivity

† To whom correspondence should be addressed.

E-mail: ccwu@dragon.nchu.edu.tw and thickness of the dielectric layer coated on the $C^{4} \mathrm{D}$ electrodes. ${ }^{16}$ In contrast, $\mathrm{C}^{2} \mathrm{D}$ is easily constructed by microfabrication techniques and is simply measured with a conductometer. However, in general, $\mathrm{C}^{4} \mathrm{D}$ has a lower LOD $(<\mu \mathrm{M})$ than $\mathrm{C}^{2} \mathrm{D}$ for inorganic ions because $\mathrm{C}^{4} \mathrm{D}$ electrodes can sustain a larger separation field due to the lack of the Faradaic effect on the electrodes. If the Faradaic effect induced by the separation field on the electrodes can be minimized, the contacttype detection also promises ME with great potential for the measurement of different analytes. The in-channel electrode is easily affected by the electrophoretic separation field, so a lower separation field $(<100 \mathrm{~V} / \mathrm{cm})$ was used. ${ }^{18,19}$ However, the endchannel ME detection presented the high LOD at the scale of tens of micromolars and a low resolution between $\mathrm{K}^{+}$and $\mathrm{Na}^{+}{ }^{20}$ Therefore, the ME electrode configuration is an important issue for developing more sensitive detection. Our previous study found that the decoupler design can decrease the Faradaic effect of the separation field on off-channel amperometric electrodes. ${ }^{21}$ However, to the best of our knowledge, no study has reported designs of off-channel ME contact conductivity electrodes.

In principle, the sensing properties of conductometric electrodes are related to the electrode's cell constant $(d / A ; d$, distance between two electrodes; $A$, the cross-sectional area of electrode). The greater the $d / A$ is, the larger the impedimetric response is. Grass et al. proved that left-right antiparallel contact conductivity electrodes perpendicular to the ME channel easily presented a larger $d / A$ and a better resistive response than front-rear parallel electrodes measured in an isotachophoresis PMMA-microchip, ${ }^{22}$ implying that it is easier for the left-right 
antiparallel electrode configuration to obtain a larger $d / A$. In this study, top-bottom antiparallel indium tin oxide (ITO) electrodes were integrated with glass microchannels using the hot-bonding technique without expensive instruments to form the off-channel ME device. The antiparallel electrode design could decrease the stray capacitance. ${ }^{11,23}$ Moreover, the decoupler of off-channel ME could minimize the effect of the separation field on the contact conductivity electrodes. The area-varied ITO electrodes were used to form different $d / A$ values and to evaluate the effect of $d / A$ on the sensing properties of ME. $\mathrm{K}^{+}$and $\mathrm{Na}^{+}$ions were used as indexes to demonstrate the ME separation efficiency.

\section{Experimental}

\section{Reagents}

Histidine (His), MES, potassium chloride and sodium chloride were purchased from Sigma-Aldrich. A mixture of MES and His was used for BGE. Positive photoresist of S1818 and negative photoresist of SU8-3010 were respectively obtained from Shipley (Tokyo, Japan) and MicroChem (Newton, MA). Hydrochloride acid and nitric acid bought from Union Chemical Works (Hsinchu, Taiwan) were mixed as the ITO etchant. ITOcoated glass plates (ITO thickness: $260 \pm 20 \mathrm{~nm}$; resistivity $\leq 7 \Omega \mathrm{cm}$ ) were bought from Anatech (Taipei, Taiwan). All chemicals were of reagent grade and were used without further purification. All solutions were prepared with water purified through a Milli-Q system.

\section{Fabrication of electrode and ME device}

The ITO-coated glass plates were used as the ME substrate and simultaneously fabricated as the decoupler and the working electrodes using microfabrication techniques. Prior to spincoating of S1818 photoresist, the ITO plates were ultrasonically cleaned by isopropanol and acetone. After exposure and development, the patterned S1818 photoresist layer with about $2 \mu \mathrm{m}$ in thickness was used as a masking material on the cleaned ITO plates to protect the decoupler and electrode regions. To increase the resistance to the ITO etchant, the $\mathrm{S} 1818$ photoresist was sequentially baked at $90^{\circ} \mathrm{C}$ for $3 \mathrm{~min}, 120^{\circ} \mathrm{C}$ for $3 \mathrm{~min}$ and $150^{\circ} \mathrm{C}$ for $10 \mathrm{~min}$. Next, the $\mathrm{S} 1818$ photoresist-containing ITO plates were dipped in a mixture of $\mathrm{HCl}, \mathrm{HNO}_{3}$ and pure water (0.20:0.05:0.75, v/v) at $25^{\circ} \mathrm{C}$ for $2 \mathrm{~h}$. They were then dipped in acetone to remove the patterned S1818 photoresist to expose the ITO decouplers and electrodes. Four sets of the decoupler/ electrode pairs were laid out on an ITO plate to increase the chip lifespan (as shown in Fig. 1(a)), and each decoupler was placed in front of one electrode. The gap between the decoupler and the electrode in each set was $250 \mu \mathrm{m}$ The distance between the electrode of the previous set and the decoupler of the following set was $100 \mu \mathrm{m}$. The width of each decoupler was $500 \mu \mathrm{m}$. Electrodes were fabricated in three different widths $(50,75$ and $100 \mu \mathrm{m})$ for use in different microdevices to explore the effect of cell constant values on the $\mathrm{C}^{2} \mathrm{D}$. As shown in Fig. 1(a), a 10- $\mu \mathrm{m}$ thick SU8-3010 photoresist layer was formed on one of the patterned ITO electrode-containing plates as the wall of the ME microchannel and reservoir after exposure and development. Moreover, four holes were drilled in the ITO electrode-containing plates without the SU8-3010 coating corresponding to the location of the SU8-3010 photoresist reservoirs. In this study a hot-bonding technique was used to bond the patterned SU8-3010 photoresist layer (called the bottom plate of the ME device) and the other ITO electrodecontaining plates (called the upper plate of the ME device) ${ }^{24}$
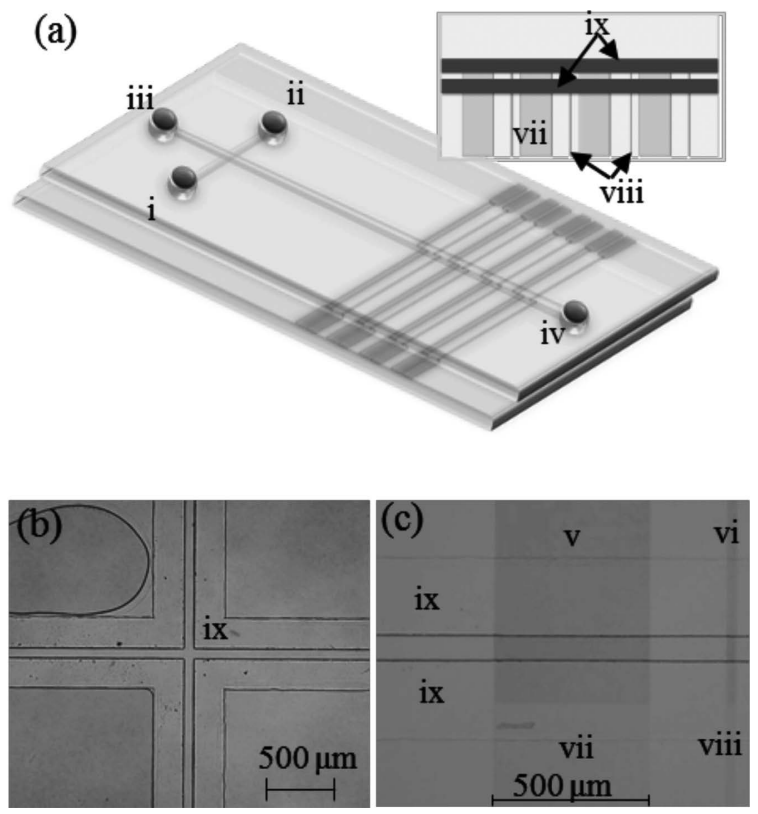

Fig. 1 (a) Scheme of the ME device integrated with four sets of top-bottom antiparallel ITO electrodes and a cross-type microchannel. The inset shows the layout of the bottom ITO electrodes and SU8-3010 walls. Optical images observed at the intercross of the cross-type microchannel (b) and the region of decouplers and electrodes (c) after bonding. (ii $-\mathrm{x}$ ) are, respectively, the sample reservoir, the sample waste reservoir, the buffer reservoir, the buffer waste reservoir, the top decoupler, the top electrode, the bottom decoupler, the bottom electrode and the SU8-3010 wall.

In order to lower the hot-bonding temperature, the SU8-3010 photoresist exposure only reached the $70 \%$ default dose $(365$ $\left.\mathrm{nm}, 155 \mathrm{~mJ} / \mathrm{cm}^{2}\right)$. After alignment with a microscope, the aligned upper/bottom plates were placed on a home-made hot bonding machine with a normal pressure of $1.3-1.5 \mathrm{kgf} / \mathrm{cm}^{2}$ and sequentially heated at $40^{\circ} \mathrm{C}$ for $1 \mathrm{~min}, 65^{\circ} \mathrm{C}$ for $3 \mathrm{~min}$, and $80^{\circ} \mathrm{C}$ for $5 \mathrm{~min}$ to form the SU8-3010/glass bond. Finally, the bonded ME devices were overexposed at a $600 \mathrm{~mJ} / \mathrm{cm}^{2}$ dose $(365 \mathrm{~nm})$ to complete the curing of the SU8-3010 photoresist. Figure 1(a) shows the bonded ME device with the cross-type microchannel and the ITO electrodes. The ME channel was $10 \mu \mathrm{m}$ in height and $75 \mu \mathrm{m}$ in width. The distance from the intercross point of the ME channels to the sample reservoir, the sample waste reservoir and the buffer reservoir was $0.5 \mathrm{~cm}$, and the effective separation length at the first-pair decoupler/ electrode was $3.93 \mathrm{~cm}$.

\section{ME procedure and measurement}

The ME high voltage was applied by using two digital highvoltage power supplies (MP-2AP; Major Science, New Taipei, Taiwan). The two power supplies can synchronize the voltage output. The EOF mobility of ME was estimated by the currentmonitoring method, ${ }^{25}$ which uses $5 \mathrm{mM}$ MES/His (pH 5.9) to replace the $10 \mathrm{mM}$ MES/His ( $\mathrm{pH}$ 5.9) filling the ME channel and applies a $100 \mathrm{~V} / \mathrm{cm}$ field between the buffer reservoir and the buffer waste reservoir.

The $\mathrm{K}^{+}$and $\mathrm{Na}^{+}$were prepared in pure water to enhance the stacking effect ${ }^{26}$ and used as an index to demonstrate the ME separation efficiency. During the injection mode, a $150 \mathrm{~V} / \mathrm{cm}$ field was applied between the sample reservoir and sample waste reservoir, and the buffer reservoir and the buffer waste reservoir were floating. The impedance of the separation zone 
(a)

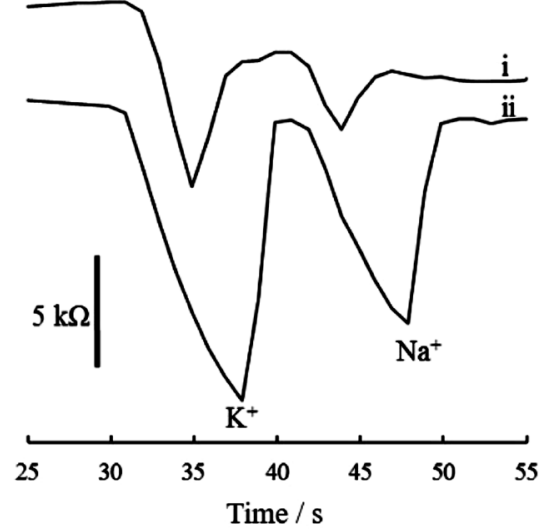

(c)

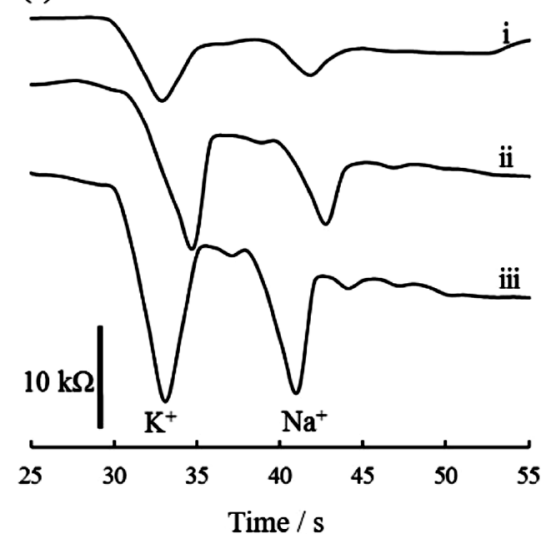

(b)

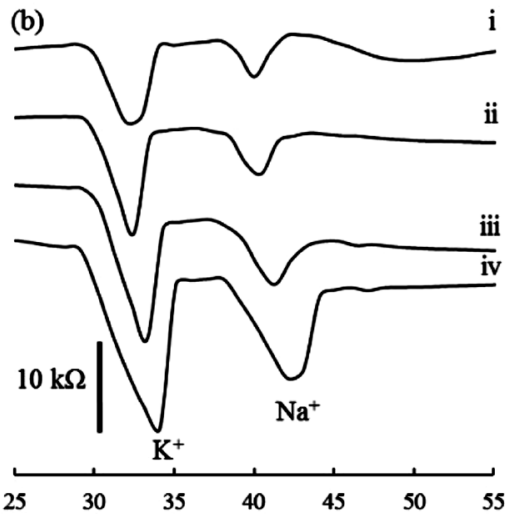

Time / s

(d)

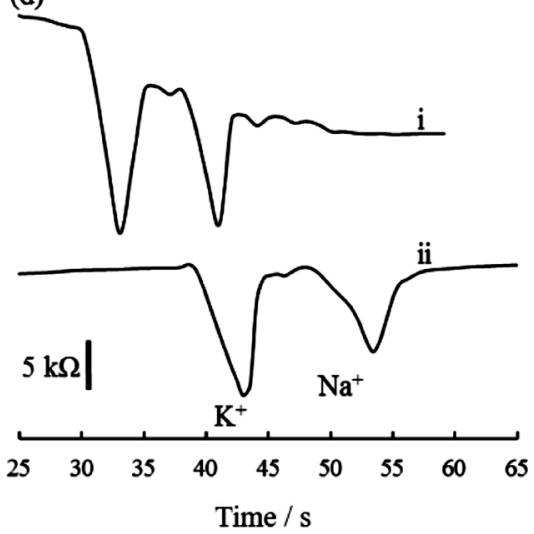

Fig. 2 Electropherograms of $1 \mathrm{mM} \mathrm{K}^{+}$and $\mathrm{Na}^{+}$(a) injected for $5 \mathrm{~s}$ (i) and $10 \mathrm{~s}$ (ii) and measured at $5 \mathrm{mV}_{\mathrm{pp}}$, (b) measured at 5 (i), 50 (ii), 100 (iii) and $200 \mathrm{mV}_{\mathrm{pp}}$ (iv), (c) in the MES/His (pH 5.9) BGE of 20 (i), 10 (ii) and $5 \mathrm{mM}$ (iii), and (d) separated with separation fields of 130 (i) and $100 \mathrm{~V} / \mathrm{cm}$ (ii) in $5 \mathrm{mM}$ MES/His BGE. All experiments were performed using $100 \mu \mathrm{m}$ wide top-bottom antiparallel electrodes at $200 \mathrm{mV}_{\mathrm{pp}}$ in $10 \mathrm{mM}$ MES/His BGE under a $150 \mathrm{~V} / \mathrm{cm}$ injection field for $5 \mathrm{~s}$ and the $130 \mathrm{~V} / \mathrm{cm}$ separation field, except as otherwise noted.

was continuously measured using an LCR meter (4284A, Agilent, Santa Clara, CA) connected with the top electrode (vi of Fig. 1) and the bottom electrode (viii of Fig. 1) in a twoelectrode mode. The LCR meter supplied the $5-200 \mathrm{mV}$ peakto-peak $\mathrm{AC}$ voltage $\left(\mathrm{V}_{\mathrm{pp}}\right)$ and $100 \mathrm{kHz}$ to determine the effect of $\mathrm{V}_{\mathrm{pp}}$ excitation voltage on the sensing properties. Moreover, the measured impedance signal was recorded by a self-designed program with the $2 \mathrm{~Hz}$ acquisition rate through the LabVIEW GPIB (Austin, TX) connection.

\section{Results and Discussion}

\section{Chip fabrication}

Figure 1(b) shows optical images of the intercross region of the two microchannels and one set of off-channel electrodes. The average width of the microchannel built by the SU8-3010 walls was $75 \pm 2.3 \mathrm{~m}$. The image of the ITO electrodes shows that the top and bottom antiparallel decouplers and electrodes are well aligned. The widths of the decoupler and conductometric electrode, shown in Fig. 1(b), were respectively $500 \pm 1.6 \mathrm{~m}$ and about $49 \pm 1.2 \mathrm{~m}$, indicating the ITO etching process has good consistency with the mask design and good reproducibility.

\section{EOF and decoupler performance}

The separating efficiency and reproducibility of the ME device are determined by the strength and stability of EOF. The EOF mobility of the ME device was $3.7 \pm 10^{-4} \mathrm{~cm}^{2} / \mathrm{Vs}$, after activating the microchannels using $1 \mathrm{M} \mathrm{NaOH}$, and could be maintained for $1500 \mathrm{~s}$ with only about a $3 \%$ decrease, indicating good stability within the period of ME operation.

The electrode configuration of off-chip ME uses a decoupler to prevent the separation field from imposing the faradaic effect on the later electrode. The faradaic effect could cause electrode deterioration and increased background noise. A good decoupler can absorb hydrogen to prevent the formation of hydrogen bubbles resulting from water electrolysis. ${ }^{21}$ The decoupling efficiency was estimated by the background current passing from the decoupler as the separation field was raised from 40 to $180 \mathrm{~V} / \mathrm{cm}$ in $5 \mathrm{mM}$ MES/His BGE, as shown in Fig. S1 (see Supporting Information). The result shows that the background current measured at the $500 \mu \mathrm{m}$ wide top-bottom antiparallel ITO decouplers was slightly smaller than that measured at a Pt wire, implying the $500 \mu \mathrm{m}$ wide ITO decoupler had a decoupling efficiency similar to that of the Pt wire in the range of 40180 $\mathrm{V} / \mathrm{cm}$. Furthermore, although the top-bottom antiparallel ITO decouplers with a surface area of $300 \times 75 \mu \mathrm{m}$ and $500 \times 75 \mu \mathrm{m}$ were larger than the cross sectional area of the microchannel 
(a)

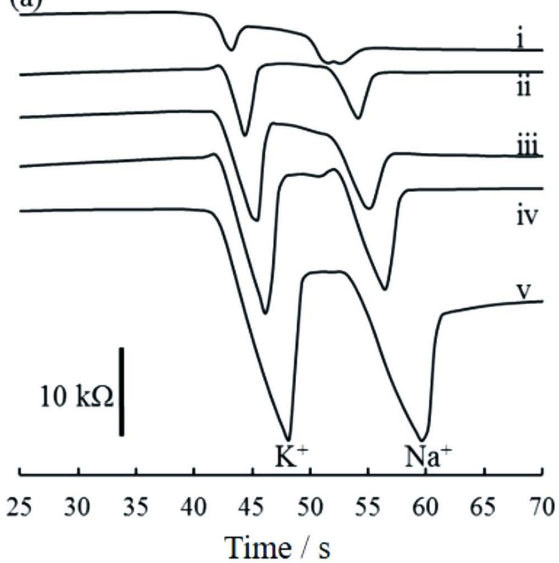

(b)

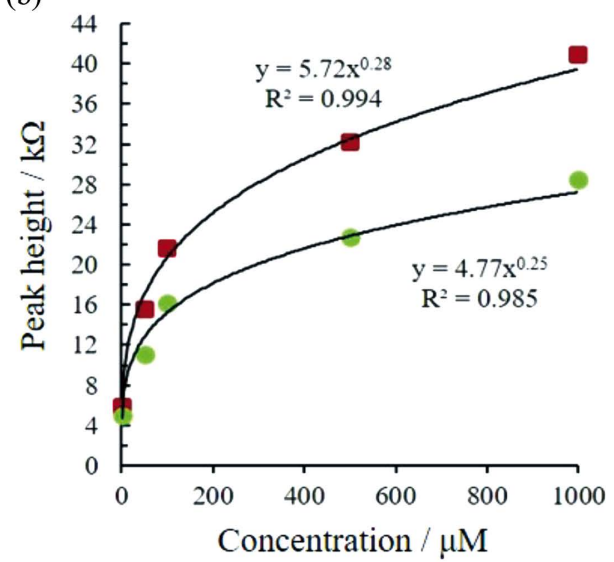

Fig. 3 (a) Electropherograms of (i) 1, (ii) 50, (iii) 100, (iv) 500 and (v) $1000 \mathrm{M} \mathrm{K}^{+}$and $\mathrm{Na}^{+}$measured at electrodes with a cell constant of $24.2 / \mathrm{cm}$. Other conditions are the same as in Fig. 3 . (b) The corresponding calibration curve of $\mathrm{K}$

$(10 \mu \mathrm{m} \times 75 \mu \mathrm{m})$, the background current of the $300 \mu \mathrm{m}$ wide top-bottom antiparallel ITO decouplers was obviously smaller than that of the $500 \mu \mathrm{m}$ wide ITO decouplers. This indicates that the larger decoupler has the better decoupling efficiency. Moreover, hydrogen bubbles only occurred on the surface of the $500 \mu \mathrm{m}$ wide ITO decouplers after applying $160 \mathrm{~V} / \mathrm{cm}$ for about $95 \mathrm{~s}$. Therefore, the separation field needs to be lower than $160 \mathrm{~V} / \mathrm{cm}$ to maintain the decoupling ability of the $500 \mu \mathrm{m}$ wide ITO decoupler.

\section{Operational conditions of $M E$ device}

The ME operational conditions were investigated to determine the optimal separation efficiency. According to the mobility of $\mathrm{K}^{+}\left(7.6 \times 10^{-4} \mathrm{~cm}^{2} / \mathrm{Vs}\right)$ and $\mathrm{Na}^{+}\left(5.2 \times 10^{-4} \mathrm{~cm}^{2} / \mathrm{Vs}\right),{ }^{27}$ the time required for $\mathrm{Na}^{+}$to move from the sample reservoir to the intercross of the microchannels was calculated as $3.75 \mathrm{~s}$ with an EOF mobility of $3.7 \times 10^{-4} \mathrm{~cm}^{2} / \mathrm{Vs}$ under a separation field of $150 \mathrm{~V} / \mathrm{cm}$. Figure 2(a) shows the electropherograms of $1 \mathrm{mM}$ $\mathrm{K}^{+}$and $\mathrm{Na}^{+}$with injection times of 5 and $10 \mathrm{~s}$, proving that the glass-based ME device can completely separate $\mathrm{K}^{+}$and $\mathrm{Na}^{+}$. The $\mathrm{K}^{+}$peak height was larger than the $\mathrm{Na}^{+}$peak height due to the larger mobility of the $\mathrm{K}^{+}$ion. Although the $\mathrm{K}^{+}$peak height of the $10 \mathrm{~s}$ injection was 1.56 times larger than that of the $5 \mathrm{~s}$ injection, the resolution (2.9) of the $\mathrm{K}^{+} / \mathrm{Na}^{+}$peak pair of the $10 \mathrm{~s}$ injection was lower than that (3.6) of the $5 \mathrm{~s}$ injection. Moreover, the peak shape of the $10 \mathrm{~s}$ injection presented an asymmetrical fronting peak, but the peak shape of the $5 \mathrm{~s}$ injection was more symmetric. Therefore, the $5 \mathrm{~s}$ injection is a better parameter for the sample injection.

Figure 2(b) shows the effect of excitation voltage on the conductometric signal for the same concentrations of $1 \mathrm{mM} \mathrm{K}^{+}$ and $\mathrm{Na}^{+}$. The $\mathrm{Na}^{+}$peak height increased proportionally with the excitation voltage in the range of $5-200 \mathrm{mV}_{\mathrm{pp}}$ with a good coefficient of determination $\left(R^{2}=0.992\right)$ and without a significant increase to background noise. However, the background noise increased obviously to reduce the $S / N$ ratio (data not shown) when the excitation voltage was performed at $250 \mathrm{mV}_{\mathrm{pp}}$, which is attributed to the Faradaic reaction of the ITO electrode. Therefore, $200 \mathrm{mV}_{\mathrm{p}-\mathrm{p}}$ was used in the following experiments to improve the $S / N$ ratio.

The detection signal of the sample zone originates from the conductance difference between the sample zone and the BGE. The conductance of the sample zone is calculated from the BGE conductivity, the analyte conductivity and the transfer ratio of the analyte. The transfer ratio of the analyte is determined by its electrophoretic mobility, the BGE co-ion and the BGE counter-ion. ${ }^{6}$ Figure 2(c) shows the effect of BGE conductivity of 5, 10, and $20 \mathrm{mM} \mathrm{MES/His} \mathrm{(pH} \mathrm{5.9)} \mathrm{on} \mathrm{the} \mathrm{sample} \mathrm{zone}$ detection signal. The peak heights of $\mathrm{K}^{+}$and $\mathrm{Na}^{+}$measured in the $5 \mathrm{mM}$ MES/His BGE $(117 \mathrm{~S} / \mathrm{cm})$ were respectively 2.85 times and 4.36 times greater than that measured in the $20 \mathrm{mM}$ MES/His BGE (438 S/cm). The result indicates that the peak height increases as the BGE concentration decreases. Because the mobility of the BGE co-ion (His) is smaller than that of $\mathrm{K}^{+}$and $\mathrm{Na}^{+}$, an asymmetric fronting peak is observed. ${ }^{28}$ To improve the $S / N$ ratio, the $5 \mathrm{mM}$ MES/His BGE was used to estimate the sensing properties of the ME devices.

Figure 2(d) shows the effect of the separation field (100 and $130 \mathrm{~V} / \mathrm{cm}$ ) on the detection signal. The $130 \mathrm{~V} / \mathrm{cm}$ separation field induced a larger peak height and greater background noise than the $100 \mathrm{~V} / \mathrm{cm}$. The increase in background noise is attributed to the interference of the electrophoretic current on the $\mathrm{C}^{2} \mathrm{D}$ electrode as the stronger separation field is applied to the off-channel ME device. The $S / N$ ratio of $\mathrm{K}^{+}$and $\mathrm{Na}^{+}$ obtained with the $130 \mathrm{~V} / \mathrm{cm}$ field was respectively 11.1 and 7.4, and 83.0 and 53.5 with the $100 \mathrm{~V} / \mathrm{cm}$. The results indicate that the $100 \mathrm{mV} / \mathrm{cm}$ field provides better separation and detection of $\mathrm{Na}^{+}$and $\mathrm{K}^{+}$in ME. Repeatability was investigated using the following ME parameters of the $150 \mathrm{~V} / \mathrm{cm}$ injection field: $5 \mathrm{~s}$, $200 \mathrm{mV}_{\mathrm{pp}}$ excitation voltage and $100 \mathrm{mV} / \mathrm{cm}$ separation field for $0.5 \mathrm{mM} \mathrm{K}^{+}$and $\mathrm{Na}^{+}$in $5 \mathrm{mM}$ MES/His BGE, Fig. S2 (see Supporting Information). The migration time of $\mathrm{K}^{+}$and $\mathrm{Na}^{+}$ was $42.8 \pm 0.6 \mathrm{~s}(n=3)$ with a RSD of $1.3 \%$, and $54.7 \pm 0.6 \mathrm{~s}$ $(n=3)$ with a RSD of $1.1 \%$. The peak heights of $\mathrm{K}^{+}$and $\mathrm{Na}^{+}$ were, respectively, $14.9 \pm 0.3 \mathrm{k} \Omega(1.9 \% \mathrm{RSD})$ and $9.0 \pm 0.4 \mathrm{k} \Omega$ (4.6\% RSD). The small RSD implies high ME separation efficiency with good repeatability.

\section{Effect of cell constant}

Top-bottom antiparallel ITO electrodes with three different electrode widths were constructed to produce different cell constants. The cell constants calibrated by the three kinds of standard $\mathrm{KCl}$ solutions, $0.4 \mathrm{mM}$ (resistivity: $17.3 \mathrm{k} \Omega \mathrm{cm}$ ), $1 \mathrm{mM}(7.0 \mathrm{k} \Omega \mathrm{cm})$ and $4 \mathrm{mM}(1.8 \mathrm{k} \Omega \mathrm{cm})$, the conductivity of which was determined by a conductimeter (Con510, Eutech Instruments), were respectively $24.2,17.2$ and $13.3 / \mathrm{cm}$ for the 
50, 75 and $100 \mu \mathrm{m}$ wide electrodes. Figure S3 (Supporting Information) shows the electropherograms of $1 \mathrm{mM} \mathrm{K}+$ and $\mathrm{Na}^{+}$ measured by the three kinds of top-bottom antiparallel ITO electrodes. The results show that the peak height clearly increased with the cell constant. The $S / N$ ratio of the $\mathrm{K}^{+}$and $\mathrm{Na}^{+}$peaks measured by the $24.2 / \mathrm{cm}$ electrode was respectively $1.3 \times 10^{3}$ and $1.0 \times 10^{3}$, which was 15.9 and 19.4 times the $S / N$ ratio measured by the $13.3 / \mathrm{cm}$ electrode. The results indicate that the larger cell constant electrodes can obtain improved detection signals.

\section{Calibration curve of $M E$ device}

The ME devices integrated with the off-channel top-bottom antiparallel electrodes with a cell constant of $24.2 / \mathrm{cm}$ were used to obtain the calibration curve. Figure 3 shows the electropherograms of $1-1000 \mu \mathrm{M} \mathrm{K} \mathrm{K}^{+}$and $\mathrm{Na}^{+}$and their corresponding calibration curves. The calculated plate number of all concentrations of $\mathrm{K}^{+}$and $\mathrm{Na}^{+}$exceeds $27.6 \times 10^{3} / \mathrm{m}$, and the largest plate numbers of $\mathrm{K}^{+}$and $\mathrm{Na}^{+}$were respectively $170.8 \times 10^{3} / \mathrm{m}$ and $105.3 \times 10^{3} / \mathrm{m}$, which are greater than that of in-channel ${ }^{10,11,18,26}$ ME devices equipped with conductivity detection. Furthermore, the resolution corresponding to 1, 50, 100,500 and $1000 \mu \mathrm{M}$ was respectively $4.1,2.8,2.2,1.8$ and 1.6. The good resolution results imply that the ME devices have great promise to separate other metal ions.

The calibration curves of $\mathrm{K}^{+}$and $\mathrm{Na}^{+}$can be represented by the power functions with regression equations of $y(\mathrm{k} \Omega)=$ $5.72\left[\mathrm{~K}^{+}\right]^{0.28}(\mu \mathrm{M})\left(R^{2}=0.994\right)$ and $y(\mathrm{k} \Omega)=4.77\left[\mathrm{Na}^{+}\right]^{0.25}(\mu \mathrm{M})$ $\left(R^{2}=0.985\right)$ in the detecting range of $1-1000 \mu \mathrm{M}$. It is worth noting that the slope in the range of lower $\mathrm{K}^{+}$and $\mathrm{Na}^{+}$ concentrations is larger than that in the range of higher $\mathrm{K}^{+}$and $\mathrm{Na}^{+}$concentrations. This is attributed to the influence of fieldamplified sample stacking (FASS). ${ }^{29}$ In the ME experiments, the $\mathrm{K}^{+}$and $\mathrm{Na}^{+}$ions were prepared in distilled water. The sample plug of lower $\mathrm{K}^{+}$and $\mathrm{Na}^{+}$concentrations has lower conductivity than the $5 \mathrm{mM} \mathrm{MES} / \mathrm{His}$ BGE $(117 \mathrm{~S} / \mathrm{cm})$, implying that the field strength across the sample plug is larger than that across the BGE zone. The FASS can drive the $\mathrm{K}^{+}$and $\mathrm{Na}^{+}$to accumulate in the interface between the sample plug and the BGE, causing a larger peak height. In contrast, the higher $\mathrm{K}^{+}$and $\mathrm{Na}^{+}$concentrations decrease the application of FASS The resistance signals of $1 \mu \mathrm{M} \mathrm{K}^{+}$and $1 \mu \mathrm{M} \mathrm{Na}^{+}$separation peaks were respectively 5.9 and $5.0 \mathrm{k} \Omega$, which are greater than three times the background noise $(0.56 \Omega)$ calculated within a $15 \mathrm{~s}$ interval prior to the $\mathrm{K}^{+}$separation peak. The LOD for $\mathrm{K}^{+}$ and $\mathrm{Na}^{+}$ion can be defined as $1 \mathrm{M}$. The electrode configuration and sensing properties of the ME device were compared with the results of previous studies as listed in Table S1 (Supporting Information). The combination of the FASS effect and the ME devices integrated with the top-bottom antiparallel ITO electrodes with the off-channel $\mathrm{C}^{2} \mathrm{D}$ had significantly lower LOD than the in-channel ${ }^{18}$ and end-channel ${ }^{20}$ contact-type $^{2}$ devices and exhibited comparable properties to the in-channel $\mathrm{C}^{4} \mathrm{D}$ devices. ${ }^{30-32}$

\section{Conclusions}

In this study, top-bottom antiparallel ITO electrodes and SU83010 wall-like microstructures were fabricated to form offchannel ME devices. The $150 \mathrm{~V} / \mathrm{cm}$ injection field for $5 \mathrm{~s}$ and $100 \mathrm{~V} / \mathrm{cm}$ separation field allowed the ME separation to obtain more symmetric peaks and an improved $S / N$ ratio. Moreover, the $200 \mathrm{mV}_{\mathrm{pp}}$ excitation voltage and the use of $5 \mathrm{mM} \mathrm{MES/His}$ BGE can further promote the $S / N$ ratio of $\mathrm{K}^{+}$and $\mathrm{Na}^{+}$peaks.
The larger cell constant constructed using $50 \mu \mathrm{m}$ wide electrodes can increase the peak height and the $S / N$ ratio. The ME devices with adequate detection and separation conditions presented good coefficients of determination in a range of $1-1000 \mu \mathrm{M}$ and a LOD of $1.0 \mu \mathrm{M}$ for $\mathrm{K}^{+}$ion and $1.0 \mu \mathrm{M}$ for $\mathrm{Na}^{+}$ion. The combination of the FASS effect and the ME devices integrated with the top-bottom antiparallel electrodes and the off-channel $C^{2} \mathrm{D}$ presented detection properties superior to the present inchannel and end-channel $\mathrm{C}^{2} \mathrm{D}$ ME devices. The findings suggest the off-channel $\mathrm{C}^{2} \mathrm{D} \mathrm{ME}$ devices have great potential for use in the measurement of inorganic and organic analytes.

\section{Acknowledgements}

This work was financially supported by the Ministry of Science and Technology of Taiwan under the grants MOST104-2313-B005-036-MY3 and MOST104-2622-B-005-007-CC2, and the "Innovation and Development Center of Sustainable Agriculture" from The Featured Areas Research Center Program within the framework of the Higher Education Sprout Project by the Ministry of Education (MOE) of Taiwan.

\section{Supporting Information}

This material is available free of charge on the Web at http:// www.jsac.or.jp/analsci/.

\section{References}

1. X. Lin, Q. Chen, W. Liu, L. Yi, H. Li, Z. Wang, and J. M. Lin, Biosens. Bioelectron., 2015, 63, 105.

2. A. Staňová, J. Marák, M. Rezeli, C. Páger, F. Kilár, and D. J. Kaniansky, J. Chromatogr. A, 2011, 1218, 8701.

3. P. Zhang, H. Nan, M. J. Lee, and S. H, Kang, Talanta, 2013, 106, 388.

4. I. Álvarez-Martos, M. T. Fernández-Abedul, A. Anillo, J. L. G. Fierro, F. J. García Alonso, and A. Costa-García, Anal. Chim. Acta, 2012, 724, 136.

5. P. Kubán and P. C. Hauser, Electrophoresis, 2015, 36, 195.

6. V. Šolínová and V. Kašička, J. Sep. Sci., 2006, 29, 1743.

7. D. B. Gunasekara, J. M. Siegel, G. Caruso, M. K. Hulvey, and S. M. Lunte, Analyst, 2014, 139, 3265.

8. D. Gunasekara, M. Hulvey, S. Lunte, and J. da Silva, Anal. Bioanal. Chem., 2012, 403, 2377.

9. P. Troška, R. Chudoba, L. Danč, R. Bodor, M. Horčičiak, E. Tesařová, and M. Masár, J. Chromatogr. B, 2013, 930, 41.

10. J. Wang, M. Pumera, G. Collins, and I. Jelínek, Analyst, 2002, 127, 719 .

11. P. Kubán̆ and P. C. Hauser, Lab Chip, 2005, 5, 407.

12. C. B. Freitas, R. C. Moreira, and M. G. de Oliveira Tavares, Talanta, 2016, 147, 335.

13. H. Zhai, J. Li, Z. Chen, Z. Su, Z. Liu, and X. Yu, Microchem. J., 2014, 114, 223.

14. J. Liu, F. Xu, S. Wang, Z. Chen, J. Pan, X. Ma, X. Jia, Z. $\mathrm{Xu}, \mathrm{C}$. Liu, and L. Wang, Electrochem. Commun., 2012, 25 , 147.

15. H. Shadpour, M. L. Hupert, D. Patterson, C. Liu, M. Galloway, W. Stryjewski, J. Goettert, and S. A. Soper, Anal. Chem., 2007, 79, 870.

16. W. K. T. Coltro, R. S. Lima, T. P. Segato, E. Carrilho, D. P. de Jesus, C. L. do Lago, and J. A. F. da Silva, Anal. Methods, 2012, 4, 25. 
17. A. J. Zemann, Electrophoresis, 2003, 24, 2125.

18. R. M. Guijt, E. Baltussen, G. van der Steen, R. Schasfoort, S. Schlautmann, H. A. Billiet, J. Frank, G. W. van Dedem, and A. van den Berg, Electrophoresis, 2001, 22, 235.

19. M. Galloway, W. Stryjewski, A. Henry, S. M. Ford, S. Llopis, R. L. McCarley, and S. A. Soper, Anal. Chem. 2002, 74, 2407.

20. E. X. Vrouwe, R. Luttge, W. Olthuis, and A.van den Berg, J. Chromatogr. A, 2006, 1102, 287.

21. C. C. Wu, R. G. Wu, J. G. Huang, Y. C. Lin, and H. C. Chang, Anal. Chem., 2003, 75, 947.

22. B. Grass, D. Siepe, A. Neyer, and R. Hergenröder Fresenius' J. Anal. Chem., 2001, 371, 228.

23. J. Wang and M. Pumera, Anal. Chem., 2002, 74, 5919.

24. S. G. Serra, A. Schneider, K. Malecki, S. E. Huq, and W. Brenner, in Proceedings of 3rd International Conference on Multi-Material Micro Manufacture, 2007, Borovets, Bulgaria, 43.
25. L. C. Chen, C. C. Wu, R. G. Wu, and H. C. Chang, Langmuir, 2012, 28, 11281.

26. M. C. Breadmore and P. R Haddad, Electrophoresis, 2001 , 22, 2464.

27. A. J. Bard and L. R. Faulkner, "Electrochemical Methods Fundamentals and Applications", 2nd ed., 2001, John Wiley \& Sons Inc., New York.

28. J. L. Beckers and P. Boček, Electrophoresis, 2003, 24, 518.

29. R. Bharadwaj and J. G. Santiago, J. Fluid Mech., 2005, 543, 57.

30. M. Pumera, J. Wang, F. Opekar, I. Jelínek, J. Feldman, H. Löwe, and S. Hardt, Anal. Chem., 2002, 74, 1968.

31. K. A. Mahabadi, I. Rodriguez, C. Y. Lim, D. K. Maurya, P. C. Hauser, and N. F. de Rooij, Electrophoresis, 2010, 31, 1063.

32. J. Tanyanyiwa and P. C. Hauser, Anal. Chem., 2002, 74, 6378 